\title{
A FALTA DE USABILIDADE IMPEDE O ACESSO À INFORMAÇÃO E CONSEQUENTEMENTE O EXERCÍCIO DA CIDADANIA
}

\author{
Maria Celi Neto Ferreira ${ }^{1}$ \\ Cayley Guimarães ${ }^{2}$ - Orientador \\ 1mcnf59@yahoo.com.br; 2profcayley@yahoo.com.br
}

Curso de Comunicação Digital, Educação e Mídias Interativas - Uni-BH (www.unibh.br)

\begin{abstract}
Resumo:
Esse artigo analisa um site do governo de Minas Gerais do ponto de vista da usabilidade para verificar como a falta desse quesito impede a cidadania. As demandas do "Fale Conosco" e a enquete proposta no site serviram como indícios do problema. Para a comprovação da falta de usabilidade foram feitas avaliações heurísticas, segundo os critérios de Jakob Nielsen. Em seguida, foram realizados testes com usuários. Muitas inconformidades encontradas foram corrigidas, gerando vários ganhos para o site do Instituto, inclusive um selo de qualidade avançada que poucos sites do governo alcançaram. As análises e conclusões desse estudo mostram que a falta de usabilidade impede o exercício da cidadania no contexto analisado.
\end{abstract}

Palavras-chave: Cidadania.. Usabilidade. Heurística.

\begin{abstract}
-
This article examines the site the government of Minas Gerais in terms of usability to see how the lack of concern prevents citizenship. The demands of the "Contact Us" and survey the proposed site served as evidence of the problem. For the proof of the lack of usability heuristic evaluations were made according to the criteria of Jakob Nielsen. Then tests were carried out with users. Many non were corrected, generating more profit for the site of the Institute, including a seal of quality advanced that few government sites reached. The analysis and conclusions of this study show that the lack of usability prevents the exercise of citizenship in the context examined.
\end{abstract}

Keywords - Citizenship. Usability. Heuristics.

\section{Introdução}

Esse estudo analisa um site do Governo do Estado de Minas Gerais quanto à usabilidade e como a falta desse quesito no site impede o exercício da cidadania.
Foram analisadas as demandas do "Fale Conosco”, que é a ferramenta de comunicação entre os funcionários públicos mineiros usuários do site - e o órgão estudado, através do Portal Minas (site do Governo de Minas) e do próprio site da instituição analisada. As demandas indicaram que os usuários estavam com dificuldades no acesso às informações, gerando uma suposição da falta de usabilidade. Esse indício foi confirmado pela enquete realizada no site, em que $81 \%$ das 398 pessoas que responderam disseram não estar conseguindo acessar as informações que procuravam.

Para verificação da suposta falta de usabilidade, foram realizados testes com usuários voluntários e avaliação heurística, segundo os critérios de Jackob Nielsen.

Segundo Nielsen (2007),

“a avaliação heurística é um método de avaliação de usabilidade onde o avaliador procura identificar problemas de usabilidade numa interface com o usuário, através da análise e interpretação de um conjunto de princípios ou heurísticas."

A escolha da metodologia foi baseada em estudos de outros autores, como por exemplo, do grupo Jeffries et al (1991), que comparou diversos métodos e concluiu que a avaliação heurística foi a que apresentou melhores resultados. Já Karat, Campbell \& Fiegel (1992) recomendam em seus estudos o uso dos dois métodos, o teste com usuários e a avaliação heurística, como complementares, pois cada um identifica tipos diferentes de problema. 
Aplicando os dois métodos, esse estudo comprovou várias inconformidades em usabilidade no site analisado. Na $9^{a}$ avaliação dos sites do governo realizado pelo programa de Governança Eletrônica (E-Gov) do Estado de Minas Gerais, foram identificadas 16 inconformidades em usabilidade, de acordo com as orientações a serem seguidas na construção dos mesmos. Após as correções realizadas a partir desse estudo, as inconformidades foram reduzidas para quatro, gerando para o site da instituição um selo de qualidade avançada.

As metas que são avaliadas pela Governança Eletrônica são pactuadas no “Acordo de Resultados", que é um instrumento de avaliação de desempenho institucional dos órgãos do Governo, de iniciativa do Projeto Estruturador “Choque de Gestão” do Governo de Minas, e que, ao final de cada ano, avaliam os sites do governo estadual mineiro. De acordo com o cumprimento das normas, realiza-se uma pontuação em relação ao grau de importância dos quesitos e orientam-se as modificações necessárias para reformulação.

\section{Usabilidade e Cidadania}

Usabilidade, segundo Krug (2006) significa "assegurar-se que algo funcione bem; que uma pessoa com habilidade e experiência comuns (ou até menos) possa usar algo - seja um web site, um caça a jato ou uma porta giratória para seu propósito desejado, sem ficar frustrada com isso".

No web site, a usabilidade é que permite facilidade no acesso à informação.

\section{Guimarães (2007) afirma que a}

“usabilidade propicia eficiência na execução de tarefas, com ferramentas adequadas; uso sem grandes necessidades de aprendizado, manuais, ajudas, suporte técnico, satisfação de uso, etc."

Portanto, para que haja eficácia no diálogo entre o sistema e o usuário, é fundamental que esse sistema tenha usabilidade, principalmente porque a falta desse quesito impede o acesso à informação e consequentemente o exercício da cidadania (Santana e Guimarães, 2006).

Segundo Jardim (1999), “o direito à informação situa-se como um direito civil, um direito político e um direito social".

O exercício de tal direito, entretanto, está condicionado às possibilidades de efetivo acesso e à capacidade de entendimento da informação.

\section{Para Demo (2001), \\ “o componente central da mídia é o manejo da informação, um dos baluartes da cidadania, já que a consciência crítica necessita estar bem informada para poder ser bem exercida."}

Portanto, é imprescindível para a promoção da cidadania, um web site de fácil manuseio, que fale a língua do usuário, que seja tão consistente, "que não me faça pensar". (Krug 2006).

Quando os usuários encontram facilmente o que procuram, ou seja, quando o site tem usabilidade, eles não precisam utilizarse das formas tradicionais de atendimento, como por exemplo, das centrais de atendimento presencial ou por telefone, o que pode gerar um desafogamento dos setores. $\mathrm{O}$ sistema cumpre assim o seu papel.

Segundo Guimarães (2007),

“a usabilidade traz mais segurança, mais funcionalidade, um atendimento às reais necessidades do usuário; mais eficiência e eficácia de uso; aumento de produtividade; satisfação pessoal, etc."

Quando o sistema não tem usabilidade, não é possível realizar a tarefa, atrapalhando a vida do cidadão. Guimarães (2007) afirma também, que quando isso acontece, o sistema torna-se "inútil, no extremo brando. Ou nocivo, no extremo em que pode induzir o usuário a realizar uma tarefa de forma inadequada."

Para AmartyaSenl (2000) “a falta de oportunidade de acesso à informação prejudica o processo de participação do cidadão", dessa forma, a comunicação não é concretizada, não é eficaz e também não é exercida a cidadania. 
Jardim (1999) ressalva que “as organizações públicas devem ir além da disponibilização de um simples folder eletrônico."

Apesar dos testes de usabilidade constar como norma no Guia de Referência para Elaboração do Plano de Desenvolvimento de Sítios de Informação do Governo de Minas, segundo o coordenador do E-Gov, Fabrício Salum ${ }^{1}$, com exceção do PPP (Portal de Parceria Pública Privada), nenhum site do governo de Minas realizou esses testes, devido à falta de verba orçamentária.

\section{Governança Eletrônica}

Com o desenvolvimento da internet, surge um novo conceito denominado E-Goverment (Governo Eletrônico). De acordo com Grosvald (1999), "as novas ferramentas promovem a realização do diálogo entre Estado-Estado e EstadoCidadão".

Takasahi (2000) afirma que a grande contribuição que as tecnologias de informação podem dar ao relacionamento do governo com os cidadãos é “uma administração pública mais transparente, eficaz e voltada para a prestação de informações e serviços à população".

E são muitas as possibilidades do uso das tecnologias de informação e comunicação pela máquina administrativa pública, como por exemplo, a emissão de contracheques, formulários para solicitação de benefícios, prestação de informações ligadas aos direitos e deveres do cidadão, dentre outras, "o que impõe por parte do governo a adoção de meios digitais em benefício da eficácia, transparência e governança", segundo Grosvald (1999).

Com a finalidade de buscar rumos e possíveis diretrizes de um programa de ações rumo à Sociedade da Informação no Brasil, o Ministério da Ciência e Tecnologia convidou um grupo de mais de 300 pessoas do país e exterior. Tal programa traduziria em projetos concretos e após a aprovação pelo Conselho Nacional de Ciência e Tecnologia, em dezembro de 1998, resultou na publicação do chamado Livro Verde: “...nunca [...]

\footnotetext{
${ }^{1}$ Entrevista pessoal no dia 18/04/2009
}

plenamente maduro, nem nas idéias nem no estilo,mas sempre verde, incompleto, experimental."

Da mesma forma, em Minas Gerais existem normas definidas para os sites do governo, de maneira à universalização de serviços para a cidadania e que também, a cada ano passam por mudanças visando acomodar novas necessidades, revisar prioridades e definir metas para melhor atender ao cidadão.

No topo da hierarquia temos o Comitê de Governança Eletrônica (E-Gov), citado anteriormente. O comitê foi criado por meio do Decreto Estadual $n^{\circ} 43.666 / 03$ com base no W3C (World Wide Web Consortium). O W3C sugere uma lista de pontos de verificação das diretivas de um site Web (Checklist).

O Checklist é o método utilizado pelo E-Gov para verificar dentre outros quesitos, a usabilidade dos sites governamentais, visando à eficácia do diálogo entre cidadão e governo e a promoção da cidadania.

\section{Falta de Usabilidade ou Exclusão Digital?}

Conforme dados fornecidos pelo Departamento de Estatística do órgão analisado, a instituição possui 750.000 segurados. Desse universo, apenas 1,99\% acessou o site no período de janeiro a agosto de 2008.

Para verificar os motivos desse pouco acesso, foi realizada uma pesquisa de campo pelo Departamento de Estatística, cujo resultado identificou que $71 \%$ dos entrevistados desconhecem a existência do site.

Visando minimizar esse problema, foi intensificada a divulgação do endereço eletrônico da instituição nas mídias disponíveis, como Jornal Mural, intranet, TV, dentre outras.

Dos usuários que disseram conhecer o site, apenas 4\% usam sempre. Quais serão os motivos? Falta de tecnologia, recursos financeiros insuficientes para compra de 
equipamentos e manutenção de provedores, ou ainda analfabetismo digital?

De acordo com Tadao Takasahi (2000), o acesso à internet é restrito a poucos:

"as tecnologias de informação e comunicação ainda não chegam à maior parte da população do planeta, em que pese o ritmo veloz de sua disseminação. Enquanto o mundo economicamente mais desenvolvido encontrase envolto em um complexo de redes digitais de alta capacidade, utilizando intensamente serviços de última geração, uma parcela considerável da população dos demais países não tem acesso sequer à telefonia básica... No Brasil, o crescimento recente das telecomunicações tem democratizado o uso do telefone. O acesso à rede Internet, contudo, ainda é restrito a poucos."

José Marques de Melo (2000) acredita que a causa da exclusão digital é sócioeconômica: "a exclusão digital é uma mera projeção da exclusão cultural e tem seu fundamento na exclusão sócio-econômica". Ele acredita que qualquer sociedade que tem cidadãos excluídos do bem estar social, evidentemente conta com um grande número de excluídos midiáticos.

“A exclusão não é, portanto, um problema comunicacional. É um problema de natureza sócioeconômica”, afirma Melo (2000).

Dados do NIC.br - Núcleo de Informação e Coordenação do Ponto BR/ 2007- confirmam a natureza do problema. Em relação ao acesso à internet via computador de mesa (desktop) ou computador portátil (laptop e notebook), a renda inferior (até $\mathrm{R} \$ 380,00$ ) impede em $98 \%$ o acesso e para aqueles cuja renda está compreendida entre $\mathrm{R} \$ 380,00$ a $\mathrm{R} \$$ 1.170,00, em 84\%. Em contrapartida, o acesso chega a $66 \%$ para aqueles cuja renda supera $\mathrm{R} \$$ 3801,00. O poder aquisitivo é, portanto um fator determinante no uso das tecnologias da informação.

Para PERUZZO (2000), “o acesso é desigual gerando novas categorias sociais, como as dos conectados e não conectados, dos incluídos e dos excluídos do acesso às redes digitais.”
Segundo o Índice de Desenvolvimento Humano e indicadores sociais da ONU (Organização das Nações Unidas),

"o acesso é desigual e beneficia as classes ricas e médias na proporção da desigualdade econômica existente dentro dos países e entre os países. $O$ Brasil está na posição 69 em qualidade de vida e desfruta a quarta pior distribuição de renda do mundo."

Peruzzo (2000) confirma que o acesso à internet tem como base as condições econômicas e políticas dos países

"Nesse panorama, como dispor de computador, de linha telefônica e ainda pagar uma taxa mensal a um provedor para poder ter acesso à Internet onde ainda se morre de fome? Como alimentar a utopia de uma Internet de todos para todos diante dessa situação?”

E mesmo que haja um gradativo aumento do acesso às tecnologias de informação, sempre haverá os excluídos, pela dinâmica tecnológica. "A cada aquisição da humanidade, novos contigentes de incluídos e excluídos, vão-se constituindo.” (PINHO 2002)

Um site do governo tem que se valer destes achados para minimizar o problema de acesso à informação e exercício da cidadania.

\section{Metodologia}

Foram duas as metodologias utilizadas nesse estudo de caso, para validação da falta de usabilidade no site analisado. O primeiro foi a Avaliação Heurística, utilizando-se dos critérios heurísticos de Jakob Nielsen.

Esse método de avaliação é baseado no julgamento do avaliador e "é um dos métodos mais informais, fáceis de aprender $e$ de executar." (GUIMARÃES, 2007).

A segunda metodologia utilizada nesse estudo foi um teste empírico com usuários [Guimarães 2008]. Foram escolhidos 10 funcionários públicos voluntários que efetivamente utilizam o sistema. A maioria (83,33\%) possui curso superior completo; $75 \%$ tem idade entre 40 e 50 anos e todos eles utilizam a internet diariamente. Os testes foram 
realizados em duas datas, agosto de 2008 e março de 2009.

As tarefas foram previamente elaboradas em diferentes níveis de complexidade, como por exemplo:

- encontrar informações para requerimento de benefícios;

- formulários e informações;

- emissão de contracheque;

- verificar licitações, etc.

A técnica utilizada foi o protocolo verbal, ou seja, o participante vai dizendo o que está fazendo e pensando enquanto realiza a tarefa. E a coleta de dados foi manual, caneta e papel. Todos os testes foram realizados no próprio ambiente de trabalho e o tempo de realização da tarefa foi cronometrado individualmente.

Após a realização das tarefas, cada voluntário avaliou, subjetivamente, o site quanto à facilidade de uso, cujos pontos variaram de 0 a 4 . Sendo $0=$ éssimo; $1=$ ruim; $2=$ regular; $3=$ bom e $4=$ ótimo .

\section{Resultados}

\section{Gráfico 1 - Demandas do "Fale Conosco"}

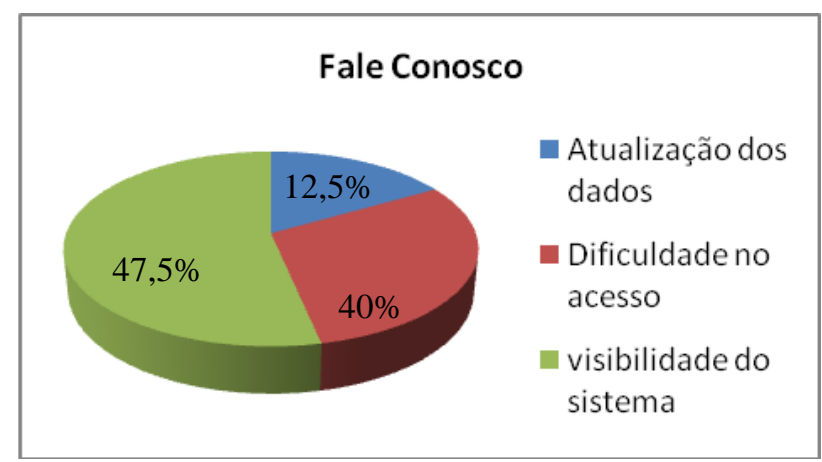

O Gráfico 1 demonstra os indícios da falta de usabilidade, tendo em vista o alto índice de dificuldade no acesso as informações e a falta de visibilidade do sistema (informações insuficientes para realizar a tarefa, links quebrados, etc), ou seja, 87,5\% são problemas de usabilidade.
Gráfico 2 - Acesso às informações

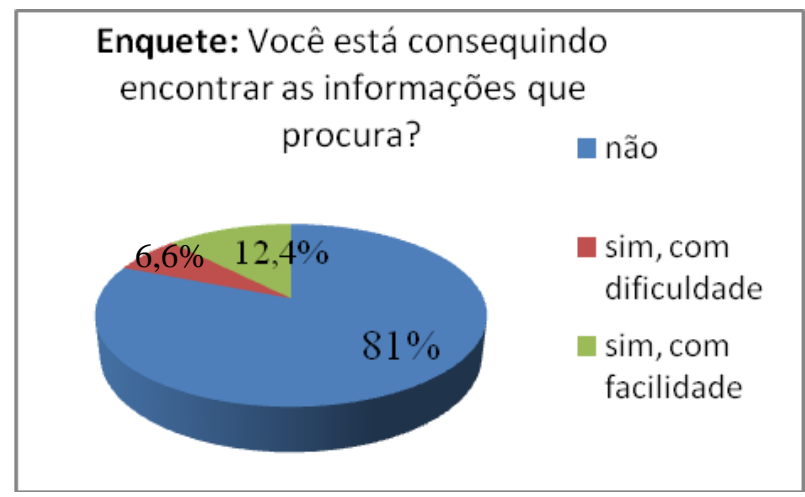

O Gráfico 2 confirma os indícios da falta de usabilidade: $81 \%$ das 398 pessoas que responderam a enquete disseram não estar conseguindo encontrar as informações que procuravam.

\section{Teste com Usuários}

A tabela 1 representa os dados coletados no período de agosto/2008.

\section{Tabela 1 - Resultados do primeiro período}

\begin{tabular}{|c|c|c|c|}
\hline $\begin{array}{c}\text { Tempo médio } \\
\text { (em minutos) } \\
\text { de execução } \\
\text { da tarefa }\end{array}$ & $\begin{array}{c}\text { Média da } \\
\text { nota do } \\
\text { site }\end{array}$ & $\begin{array}{c}\text { \% dos que } \\
\text { concluíram } \\
\text { a tarefa }\end{array}$ & $\begin{array}{c}\text { Hábito } \\
\text { diário de } \\
\text { uso da } \\
\text { Internet }\end{array}$ \\
\hline 11,5 & 1,25 & $75 \%$ & $100 \%$ \\
\hline
\end{tabular}

A tabela 2 representa os dados coletados no período de março de 2009.

\section{Tabela 2 - Resultados do segundo período}

\begin{tabular}{|c|c|c|c|}
\hline $\begin{array}{c}\text { Tempo médio } \\
\text { (em minutos) } \\
\text { de execução } \\
\text { da tarefa }\end{array}$ & $\begin{array}{c}\text { Média da } \\
\text { nota do } \\
\text { site }\end{array}$ & $\begin{array}{c}\text { \% dos que } \\
\text { concluíram } \\
\text { a tarefa }\end{array}$ & $\begin{array}{c}\text { Hábito } \\
\text { diário de } \\
\text { uso da } \\
\text { internet }\end{array}$ \\
\hline 8,12 & 0,65 & $62,5 \%$ & $100 \%$ \\
\hline
\end{tabular}

Constatou-se que, mesmo sendo elevado o percentual de utilização da internet por parte dos voluntários, em ambas as pesquisas, o tempo médio para realizar a tarefa dada foi muito alto, o que comprova claramente problemas sérios em usabilidade. Quanto à nota dada, a maioria considerou 0 site de ruim a péssimo. 


\section{Gráfico 2 - Resultados da Avaliação Heurística}

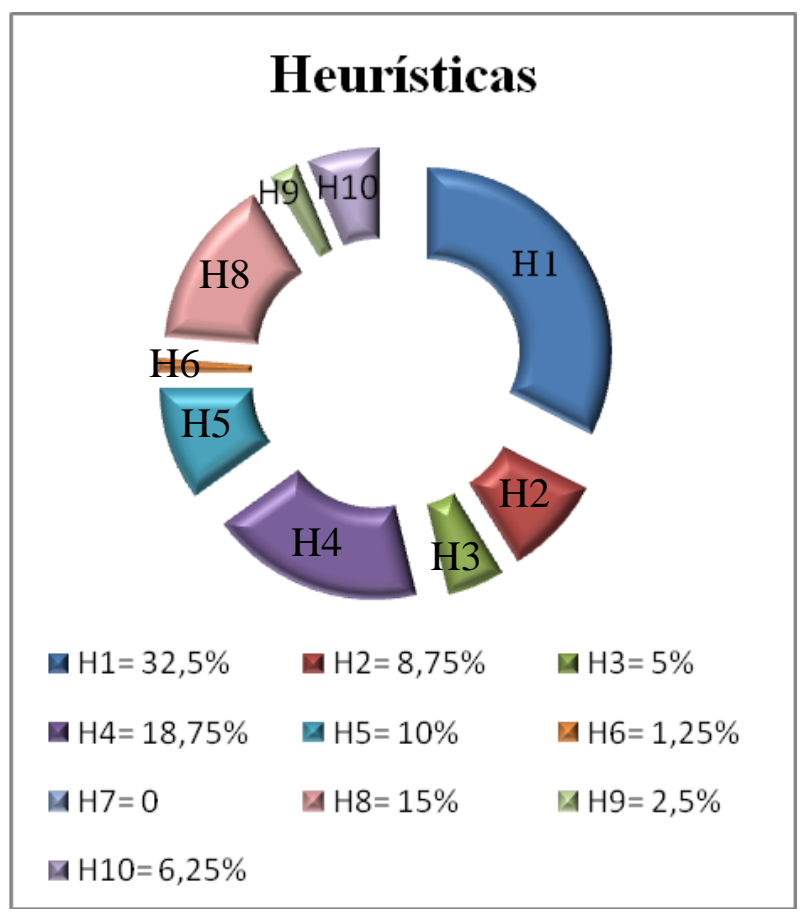

Onde H1 = Visibilidade do estado do sistema; H2= Correspondência entre o sistema e o mundo real; H3= Controle do usuário e liberdade; H4= Consistência e padrões;

H5= Prevenção de erros;

H6= Ajuda aos usuários a reconhecer, diagnosticar e recuperar erros;

H7= Reconhecimento ao invés de lembrar;

H8= Flexibilidade e eficiência de uso;

H9= Design e estética minimalista;

H10= Ajuda e documentação.

O Gráfico 2 demonstra que o maior problema encontrado foi a heurística $\mathrm{H} 1$ : visibilidade do status do sistema. Pelas análises, foram encontrados links quebrados, ou seja, as páginas não continham os conteúdos procurados; havia também pouca visibilidade dos ícones e a necessidade de utilizar-se da barra de rolagem para visualizar; o banner da Instituição se confundindo com a barra de navegação; o endereço em local pouco visível; palavras abreviadas; banners com endereços que não correspondiam ao assunto; conteúdos agrupados incorretamente, dentre outros. Essa heurística apresentou um grau de severidade 3 , ou seja, uma catástrofe em usabilidade, mas em grande parte já resolvida após esse estudo.
O segundo maior índice de ocorrência foi em relação à falta de consistência nos padrões (Heurística H4). A maior parte dos problemas foram considerados como “cosméticos" do ponto de vista da usabilidade, mas que devem ser resolvidos por estar dentro das normas da governança eletrônica.

O terceiro maior índice, flexibilidade e eficiência de uso (Heurística 8), pelo grau de importância, também já foi praticamente resolvido.

Encontrar páginas “em construção” é no mínimo incompleto, quando não irritante. Outros exemplos foram: a falta de opção de retorno à página inicial; menus que não abriam; requerimentos que não baixavam, etc, que eram problemas que não poderiam esperar.

\section{Grau de Severidade}

O Gráfico 3 comprovou que a maioria dos problemas encontrados tinham que ser resolvidos com urgência. E o que coube à autora, juntamente com o Departamento de Tecnologia da Informação as medidas foram tomadas para a resolução dos problemas verificados nesse estudo.

\section{Gráfico 3 - Resultados do Grau de Severidade dos Problemas encontrados}

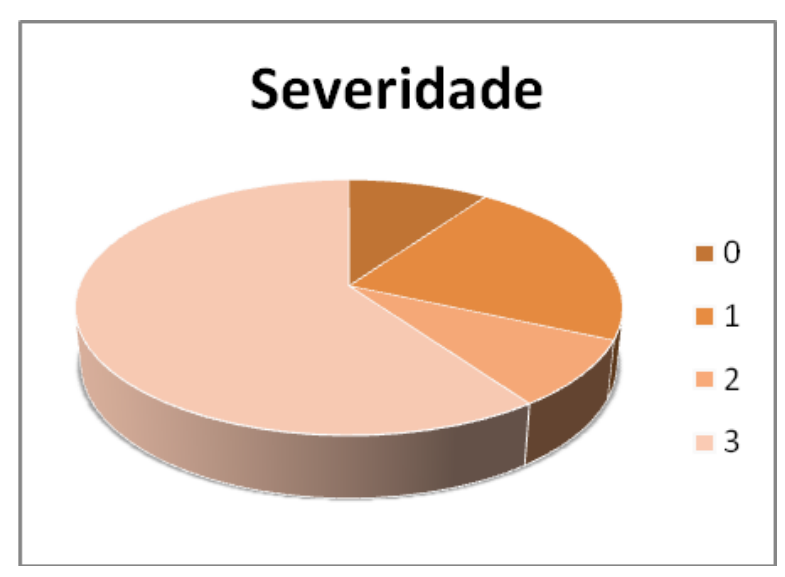

onde: $0=$ é um problema cosmético;

1 = problema de usabilidade menor, prioridade baixa;

2 = problema de usabilidade grave, alta prioridade;

$3=$ catástrofe em usabilidade, a sua correção é imperativa.

\section{Análises e Discussões}


As correções realizadas após esse estudo melhoraram, em primeiro lugar, a visibilidade do sistema. Foi retirado o banner com a foto da instituição, ampliando a área da página principal, tornando mais visíveis ícones e links importantes. Melhorou também a visualização dos menus, que ao abrir, confundia com a foto do banner. O cliente foi valorizado.

Ficou provado que a falta de usabilidade impede a cidadania, pois vários voluntários desistiram antes de concluir a tarefa dada. Após as mudanças, os desistentes foram convocados para uma nova tentativa. Para sua surpresa, dessa vez tiveram sucesso, não desistiram no meio do caminho.

Ponderamos a respeito do método Checklist e concluímos que, do ponto de vista do usuário, a avaliação heurística e os testes com usuários dão melhores resultados. Mesmo tendo conseguido uma boa pontuação na avaliação do E-Gov, o site analisado apresentou problemas de grande severidade em usabilidade.

A pesquisa também verificou a necessidade de uma maior intensificação na divulgação do endereço eletrônico do órgão, pois foi detectado um percentual alto de pessoas que desconheciam a existência do site.

Ficou também provado que não basta ter os serviços disponibilizados, o site tem que ter usabilidade. Caso contrário, os usuários não encontram as informações que procuram e não é exercida a cidadania.

Internamente, especialmente na Assessoria de Comunicação Social, foram despertados o conceito de usabilidade e a consciência de que o sistema é que tem que estar de acordo com o usuário e não o contrário. Foi também despertada essa mesma consciência nos voluntários que realizaram os testes que antes se intitularam de burros, sem habilidade e que a partir das discussões e orientações, mudaram o paradigma.

Para terminar, a exemplo do Livro Verde, demonstramos que os sistemas devem ser constantemente avaliados, as normas refeitas, levando sempre em consideração os princípios de usabilidade do ponto de vista do usuário. Somente assim, o cliente poderá efetivamente exercer sua cidadania.

Os sites do Governo podem vir a ser um dos mais eficientes e democráticos meios de promoção da cidadania, pois oferece, entre suas vantagens, o acesso remoto dos usuários aos serviços, interatividade e a simplificação de procedimentos.

Torna possível também a ampliação da capacidade operacional e sua área de cobertura. Os custos das informações disponibilizadas na web são infinitamente menores que os custos de material gráfico impresso e também são menores os recursos humanos nas transações via internet comparados com os realizados por meios tradicionais.

Realmente são altos os custos para contratação de empresa especializada em usabilidade, mas justifica-se o investimento, pois somente através de estudos dessa natureza é que se pode ter a exata noção da navegabilidade do ponto de vista do usuário.

Segundo Guimarães (2008)

"o designer é um usuário altamente
especializado e sofisticado. Ele adquire, ao
longo dos anos, uma familiaridade com as
ferramentas que o impedem de ver que alguns
elementos, por serem de uso comum e constante
para eles, não fazem parte da realidade do
usuário e, portanto, não podem ser usados
indiscriminadamente no design de sistemas. O
pressuposto de que eles entendem, que eles
conhecem, que para eles é obvio, natural e
instintivo é totalmente falho quando aplicado
ao universo do usuário. O que lhe apresenta
como óbvio é na verdade, um bicho-de-sete-
cabeças."

Nesse estudo de caso, problemas relacionados à consistência, por exemplo, não foram possíveis de ser constatados nos testes empíricos com usuários, mas nas avaliações heurísticas foram fáceis de identificar.

Portanto, os dois métodos foram considerados pertinentes para melhorar usabilidade do site, facilitar 0 acesso às informações e consequentemente promover a cidadania. Segundo Dias (2007): 
“O teste empírico com usuários é capaz de identificar sintomas dos problemas de usabilidade, enquanto a avaliação heurística está mais voltada à identificação das causas dos problemas, sendo assim, mais útil na solução de problemas encontrados.” (DIAS 2007).

Assim como o Livro Verde, nunca plenamente maduro, sempre verde, incompleto, os sites do governo precisam constantemente ser avaliados e nas correções, deve prevalecer o foco no usuário.

De acordo com Guimarães (2008),

\begin{abstract}
"uma vez entendido, por parte do designer das conseqüencias graves que a falta de usabilidade trazem para o usuário e da outra parte, o usuário entendido que nem sempre a culpa é dele pelo não funcionamento de determinado sistema, venha a se tornar mais consciente de que ele deve apontar ao designer quando estas falhas ocorrem. Ganha-se assim a oportunidade de desenvolvimento de sistemas mais adequados"
\end{abstract}

\section{Trabalhos Futuros}

Apesar da boa pontuação que o site analisado obteve nas últimas avaliações do E-Gov, muitos problemas de usabilidade ainda existem por resolver.

Por exemplo, a visibilidade do sistema. Os conteúdos foram agrupados em apenas 2 (duas) categorias, ignorando outros importantes. No teste com usuários, os voluntários ao realizar a tarefa referente a esse serviço, tiveram grande dificuldade em qual menu deveria entrar para procurar o serviço. Isso é um grave e sério problema de usabilidade que remete a uma reformulação da arquitetura da informação. Fica aqui a sugestão.

Deverão ser corrigidas para a próxima avaliação dos sites, as seguintes inconformidades:

- Não apresenta URL fácil de identificar;

- Os links visitados não são diferenciados;
- Falta informação do formato e tamanho dos arquivos para download em alguns documentos;

- Falta de abertura de links em uma nova janela em alguns formulários.

Além desses erros de usabilidade apontados, ficou constatada a necessidade de atualização dos conteúdos do site, uma vez que estão disponíveis, por exemplo:

- Lista de médicos que já não estão no quadro geral da instituição;

- Funções que exigem do usuário um cadastro e não é informado como ele deve proceder para se cadastrar;

- Hospitais listados como conveniados que na realidade não são mais;

Enfim, dados que não deviam estar publicados antes de uma prévia verificação e atualização.

O responsável pela Diretoria de Relacionamento, Desenvolvimento e Informações da Dataprev, Rogério Mascarenhas, acredita que é responsabilidade da área de TI zelar pela integridade e qualidade dos dados de uma empresa, tal qual o banco central se posiciona como guardião da moeda de um país, pois

"de nada adianta criar sistemas de informação com a melhor tecnologia para sua disponibilização, se não se assegurar que as aplicações estão corretas, consolidadas e atualizadas e garantir que os dados estão sendo manuseados correta e seguramente", diz Mascarenhas.

\section{Conclusão:}

A pesquisa encontrou uma série de problemas de usabilidade no site analisado e mostrou que a falta de usabilidade impede o acesso à informação e, portanto, a cidadania. As correções dos problemas encontrados apresentaram melhoras significativas neste 
aspecto, gerando inclusive uma premiação para o site.

Para que seja promovida a cidadania, não basta ter os serviços disponíveis: o site tem que ter usabilidade. Os cidadãos têm que, em primeiro lugar, encontrar as informações que precisam e depois, entender as orientações sobre os procedimentos. Se o web site não tem usabilidade, ele de início já não consegue com facilidade encontrar o que está procurando.

O sistema deve, portanto, ter conteúdos de alta qualidade e compatíveis com o mundo real e atualizações constantes; tem que ter clareza na arquitetura da informação; facilidade de uso; tem que permitir liberdade e facilidade de navegação; enfim, que seja elaborado para que qualquer tipo de usuário seja "sofisticado" ou com pouca habilidade consiga resolver seus problemas e exercer sua condição de cidadão.

\section{Bibliografia}

BARBALHO, Célia Regina Simonetti. Portais Eletrônicos: estudo comparativo da oferta em comunicação.

www.portcom.intercom.org.br/www_antigo/po rtcom2/endocom2004/Barbalho, acessado em $11 / 08$

CASTRO, Cosette Espíndola de; BARBOSA FILHO, André. A Nova Ordem Tecnológica: Um ensaio a partir da ética e da política.Verso e Reverso - Revista da Comunicação. www.versoereverso.unisinos.br/index.php? $=5$ $\underline{\text { \&s}=9 \& a=51}$, acessado em 11/2008

CASTELLS, Manuel. A Galáxia da Internet: reflexões sobre a internet, negócios e a sociedade. Rio de Janeiro: Jorge Zahar Ed, 2003 - Capítulo 5: A política da Internet I: redes de computadores, sociedade civil e o Estado - pág. 128 a 215.

Manual do Portal Minas - Checklist dos padrões de usabilidade de sítios governamentais

Decreto 43666 de novembro de 2003.
DEMO, Pedro. Cidadania Pequena: fragilidades e desafios do associativismo no Brasil - Campinas, SP: Autores Associados, 2001 - Coleção polêmicas do nosso tempo;80)

DIAS, Claudia. Usabilidade na Web. Criando portais mais acessíveis. Rio de Janeiro, RJ: Editora Alta Books Ltda, 2007 $2^{a}$ Edição. 296 p.

Guia de Referência para Elaboração do Plano de Desenvolvimento de Sítio de Informação Governança Eletrônica Minas On-line.

GUIMARÃES, Cayley. Usabilidade no dia-adia. A interação de seres humanos com sistemas. - Belo Horizonte: Fundac-BH, $2008.395 \mathrm{p}$.

KRUG, Steve. Não me faça pensar. Rio de Janeiro: Alta Books, 2006.

LivroVerde.

www.mct.gov.br/index.php/content/view/1887 8.html

NIELSEN, Jakob e TAHIR, Marie. Homepage usabilidade: 50 websites descontruídos. Rio de Janeiro: Campus, 2002.

NIELSEN, Jakob. Projetando Websites. Rio de Janeiro: Campus, 2000.

http://www.nap.coppe.ufrj.br/2007/v1/noticia/i ndex_noticia.php?id=25371, acessado em 04/2009

PANTOFA, Verônica Costa; BETINI, Roberto César; PEREIRA JÚNIOR, Lourival da Conceição; YAMAGUCHI, Jone Kazuki. Tecnologia da Informação e Comunicação e a Sociedade da Informação: uma contribuição para inclusão. www.intercom.org.br , acessado em 11/2008.

PERUZZO, Cicília; BRITTES, Juçara. Sociedade da Informação e Novas Mídias: participação ou exclusão? São Paulo: Intercom, 2002. 135 p.

Resolução Seplag no 40/2008 e o Anexo I da Resolução Seplag n $n^{0}$ 72/2003

SCHWINGEL, C.A. Comunicação e Criação na Internet: a sistemática de trabalho das equipes de desenvolvimento web e dos 
grupos de desenvolvimento de softwares. http://www2.metodista.br/unesco/agora/mapa http://www. animadores_pesquisadores_roseli.pdf, geocities.com/claudiaad/acessibilidade_web.ht acessado em 02/2009 $\underline{\mathrm{ml}}$

TEIXEIRA, L.H.P. Usabilidade no Design de Interface, uma questão de semiótica da http://bdtd2.ibict.br/index.php?option=com_wr apper\&Itemid $=40$, acessado em 02/2009 comunicação. Intercom: 2005.

World Wide Web Consortium (W3C)http://www.w3.org/TR., acessado em 02/2009 